\title{
Genetic therapies, human genetic enhancement, and ... eugenics?
}

\author{
Theodore Friedmann ${ }^{1}$
}

Received: 7 May 2019 / Accepted: 7 May 2019 / Published online: 4 July 2019

(c) Springer Nature Limited 2019

\section{Introduction}

Human and molecular genetics have made remarkable advances recently in developing an understanding of human biology in health and in disease. We now know in great detail the mechanisms underlying the cause of many human diseases and have devised some remarkably effective pharmacological and genetic treatments for a rapidly growing number of these diseases. This journal and other biomedical publications have documented many of these important developments, especially those dealing with disease screening methods, the detection and characterization of the genetic components of disease, the development of "personalized" and "precision" medicine, and the use of chemical biology and pharmacogenetics to design effective therapeutic agents. High among these achievements is, of course, the birth and maturation of the concepts and tools of gene therapy and related gene-based therapies that make possible new forms of modifying and ameliorating the genetic defects underlying disease rather than relying entirely on purely symptom-based forms of treatment. As promising and, in some cases, even as amazing as those advances are, biomedicine is obviously now on the cusp of even more remarkable advances toward understanding and treating human disease as a result of the development of the concepts and tools of genome editing that potentially permit definitive correction of the genetic components that cause inherited and perhaps some acquired diseases.

In the blazingly rapid period of only a few decades, these tools have already progressed from curiosities of somatic cell genetics in the laboratory to early-stage clinical application in individual human patients. Genome editing studies have reached this clinical stage for applications toward

Theodore Friedmann

tfriedmann@ucsd.edu

1 School of Medicine, University of California San Diego, La Jolla, CA, USA preventing and correcting genetic and even infectious diseases, including HIV AIDS [1], forms of leukemia [2], mucopolysaccharidoses I (https://clinicaltrials.gov/ct2/ show/NCT02702115) and II (https://clinicaltrials.gov/ct2/ show/NCT03041324), sickle cell disease [3], and others. Such genetic manipulation has been extended to genome editing studies in the human embryo identified to be at risk for a potentially dangerous or lethal disease. Proof of that concept has been provided for CRISPR-Cas9 genome editing correction in a preimplantation human embryo of a mutation responsible for the potentially lethal disease hypertrophic cardiomyopathy [4]. With unsettling speed, the door has now clearly been cracked even further open for human embryonic genetic modification by a recent announcement from China of purported HIV prevention in a subsequent generation by genome editing knockout of the CCR5 HIV co-receptor followed by birth of potentially HIV-resistant human infants [5]. As reported, the manipulation was widely regarded to be scientifically premature, technically flawed, and ethically indefensible, but the embryo genetic modification genie is probably already out of the bottle. The technical and ethical hazards of such applications have been discussed and will continue to be of major concern, even in the case of disease prevention and treatment.

\section{From therapy to genetic enhancement}

When aimed at aberrant functions causing disease, genetic manipulations such as "traditional" gene therapy and, more recently, genome editing, constitute legitimate therapy and are medically and ethically justifiable. But the potential applications for genetic modification do not stop with prevention and treatment of human disease. Gene-based therapies are one thing, but the intentional modification of the human genome to "improve" individuals, i.e., genetic enhancement, is quite another and beset with different sets of ethical and policy dilemmas. The rapidly developing tools of gene therapy and genome editing are potentially 
just as pertinent to understanding the mechanisms underlying human development and behavior, cognitive, and intellectual traits as to the formation and function of the human personality. It would probably require no great technical innovation to leap from disease prevention and therapy to attempts to modify and "enhance" human physical and intellectual traits. The temptation to do so is and will continue to be great. The tools of biotechnology, neuroscience, and genetics will increasingly identify many of the mechanisms underlying the development and regulation of human traits, not only of physical properties but also of cognitive, intellectual, and social traits, and make them tempting targets for genetic manipulation. What will be the consequences of modifying and genetically manipulating human functions intended to improve on the "natural"? When will merely "natural" not be good enough?

\section{From genetic enhancement to eugenics?}

Deliberate application of the concept and tools of genetic enhancement of individual human beings and of the human species flows directly into the highly troubling potential for spill-over into programs for design and preferential reproduction of "more desirable" and "better" kinds of human beings - i.e., eugenics. Are we prepared to pursue, accept, and regulate applications of genetic enhancement toward eugenic goals? Humanity has a very fraught relationship with the unsettling concept and the misguided practice of eugenics. The late nineteenth century and the beginning of the twentieth century witnessed the emergence and the flourishing of the concept of eugenics-the attempt to direct human heredity and evolution to ensure procreative advantage to more "desirable" human beings and to discourage or limit reproduction by the less desirables. Such programs relied on efforts to identify and provide advantage to the "favored" and to define methods to disadvantage the "unfavored". Inspired by concepts born at the Genetics Record Office at Cold Spring Harbor, New York, criteria of social undesirability and social ills came to include the undesirable and purportedly genetic traits of poverty, criminality, mental disorders, laziness and homosexuality, and thalassophilia (love of the sea) among others [6]. There was obviously little or no truly rigorous scientific evidence of a genetic basis for these presumed genetic components. There were, instead, prejudiced and fact-free presumptions of the causes of social human ills based on imaginary pseudoscience meant to justify restricted immigration of "undesirable" populations to the US mainly from central Europe and Asia. Out of those misguided eugenic concepts emerged racist immigration policies and the disastrous US Supreme Court decision in Buck v. Bell that upheld the legality and ethical justification for implementing involuntary sterilization programs in the United States and other countries that were designed to prevent the birth of human beings identified, no matter how incorrectly, to be deficient and inferior [6]. This movement, particularly the one in the United States, was a major incubator of even harsher social programs and, in their extreme forms, to the genocidal programs of Nazi Germany.

\section{The eugenic landscape in the context of modern science}

However, the poor scientific bases for these early attempts at eugenics have given way to the proven scientific and manipulative strengths of modern human genetics that make genetic manipulation for the purposes of therapy, enhancement, and even possibly eugenic goals increasingly technically feasible. With time and with scientific advances made over the ensuing many decades, the inadequacy and the folly of such ethically and scientifically indefensible eugenic thinking of the early twentieth century became clear and rightly broadly rejected. Our understanding at that time of the possible long-term multi-generational and population effects of selective manipulations of mechanisms underlying human reproduction and evolution was seriously deficient. Even now, the possible deleterious long-term adverse genetic effects of non-therapeutic genetic enhancement and even "precision" targeted genome editing are not predictable or targeted exquisitely enough to justify their application in non-therapeutic experimental settings. We are justified, and possibly even compelled, by all current codes of ethical principles governing medical practice and biomedical research to use many of these new tools in the name of healing. But if we apply them for whimsical or even well-intentioned genetic enhancement purposes, we should be aware of our inadequate understanding of their potential for long-term and irretrievable harm, and of the likelihood that they can lead us down the path toward unwise eugenic goals. We should heed the warning attributed by some to the great American baseball player and folk philosopher Yogi Berra- -If you don't know where you're going, you'll probably end up someplace else". At the moment, we do not know where this path of human genetic enhancement and its potential extension to eugenic goals leads. If we wander in that direction, we may wind up in unexpected and societally detrimental and even disastrous places. We should be sure to tread down that road only if and when scientific, ethical, and public policy justifications are more evident than they are now.

\section{Compliance with ethical standards}

Conflict of interest T. F. declares that he has no conflict of interest. 
Publisher's note: Springer Nature remains neutral with regard to jurisdictional claims in published maps and institutional affiliations.

\section{References}

1. Tebas P, Stein D, Tang WW, Frank I, Wang SQ, Lee G, et al. Gene editing of CCR5 in autologous CD4 T cells of persons infected with HIV. N Engl J Med. 2014;370:901-10.

2. Qasim W, Zhan H, Samarasinghe S, Adams S, Amrolia P, Stafford $\mathrm{S}$, et al. Molecular remission of infant B-ALL after infusion of universal TALEN gene-edited CAR T cells. Sci Transl Med. 2017;9:eaaj2013.
3. Collins F. A CRISPR approach to treating sickle cell. 2019. https:// directorsblog.nih.gov/2019/04/02/a-crispr-approach-to-treatingsickle-cell/

4. Ma H, Marti-Gutierrez N, Park SW, Wu J, Lee Y, Suzuki K, et al. Correction of a pathogenic gene mutation in human embryos. Nature. 2017;548:413-9.

5. Regalado A. EXCLUSIVE: Chinese scientists are creating CRISPR babies. MIT Technology Review. 2018. https://www. technologyreview.com/s/612458/exclusive-chinese-scientists-arecreating-crispr-babies/

6. Kevles D. In the name of eugenics. Cambridge: International Society for Science and Religion; 2007. 